\title{
The effect of polymorphism on the lithium storage performance of
}

\author{
$\mathrm{Li}_{2} \mathrm{MnSiO}_{4}$ \\ Vishwanathan Ramar ${ }^{\mathrm{a}}$ and Palani Balaya ${ }^{\mathrm{a}^{*}}$ \\ ${ }^{a}$ Department of Mechanical Engineering, National University of Singapore, \\ Singapore 117576 \\ *E-mail address: mpepb@nus.edu.sg; Tel: +65 6516 7644; Fax: +65 67791459
}

\begin{abstract}
We report the synthesis of low and high temperature polymorphs of $\mathrm{Li}_{2} \mathrm{MnSiO}_{4}$ and dependence of lithium storage performance on such polymorphs. Two polymorphs namely, $P m n 2_{1}$ (low temperature/orthorhombic polymorph) and $P 2_{1} / n$ (high temperature/monoclinic polymorph) are isolated by controlling the calcination temperature. Among them the electrochemical performance of $P m n 2_{1}$ is found to be better than $P 2_{1} / n$. Orthorhombic polymorph $\left(P m n 2_{1}\right)$ of carbon coated $\mathrm{Li}_{2} \mathrm{MnSiO}_{4}$ exhibits an impressive discharge capacity of $262 \mathrm{mAh} \mathrm{g}^{-1}$ at $0.1 \mathrm{C}$ and rate performance up to $5 \mathrm{C}$; in contrast $P 2_{1} / n$ delivers only a discharge capacity of $164 \mathrm{mAh} \mathrm{g}^{-1}$ at $0.1 \mathrm{C}$ at room temperature. Notably, the capacity of $P m n 2_{1}$ phase is almost $1.5-2$ times higher than $P 2_{1} / n$ phase at all current rates. Capacity retention of $90 \%$ is reported for orthorhombic polymorph until 30 cycles at $0.1 \mathrm{C}$. Further the voltage profiles and polarization of orthorhombic phase are much better than the monoclinic phase. Such perceivable differences in the rate performances and voltage profiles is argued to be due to variations in the activation energy barrier and hopping distance of lithium ion in the crystal structures. Besides the role of polymorphism, we also show here that the structural stability during cycling is critical in retaining high storage performance.
\end{abstract}


Keywords: $\mathrm{Li}_{2} \mathrm{MnSiO}_{4}$; Polymorphs; Polyanion; Cathode; Low polarization; Carbon coating;

\section{Introduction}

Despite tremendous success of lithium-ion batteries (LIBs), their low energy density has always been a matter of great concern.[1-4] One way to improve the energy density of LIBs is to use cathode materials with high lithium storage capacities.[5-7] $\mathrm{Li}_{2} \mathrm{MnSiO}_{4}$ has a high theoretical capacity of $333 \mathrm{mAh} \mathrm{g}^{-1}$, assuming 2 moles of lithium ion transfer per formula unit.[8-15] Besides high capacity, they are attractive owing to their low cost, environmental friendliness and safety which arises from the integration of $\left(\mathrm{SiO}_{4}\right)^{4-}$ polyanion (strong $\mathrm{Si}-\mathrm{O}$ bonds) in the crystal structure. $[6,9,16]$ However, $\mathrm{Li}_{2} \mathrm{MnSiO}_{4}$ suffers from very low intrinsic electronic conductivity $\left(10^{-14}\right.$ to $\left.10^{-16} \mathrm{~S} \mathrm{~cm}^{-1}\right)$ resulting in poor electrochemical performance. $[17,18]$ To improve the lithium storage performance most of the previous works have focussed on nano-structuring this active material and providing carbon coating.[14, 15, 19-27] One striking aspect of $\mathrm{Li}_{2} \mathrm{MnSiO}_{4}$ is their richness in polymorphism.[6, 8-10, 28-30] Different polymorphs have been previously prepared by carefully controlling the several parameters such as temperature, pressure, ramp up and ramp down rate of temperature for the synthesis and post-treatment of the materials.[6, 8-13, 30-33] For instance, two low temperature polymorphs $P m n 2_{1}$ and $P m n b$ with an orthorhombic structure, $[10,11,34]$ a high temperature polymorph $P 2_{1} / n$ with a monoclinic structure[35] and a meta-stable monoclinic $P n$ polymorph[36] have been reported till date. In general, insertion and extraction of less than one mole of lithium has been reported for $\mathrm{Li}_{2} \mathrm{MnSiO}_{4}$. However, there are a few reports which exploited second lithium exchange. Insertion and extraction of more than one mole of lithium is reported for (low temperature) $P m n 2_{1}$ polymorph at room temperature (RT) $[15,24$, 37-39] and for (high temperature) $P 2_{1} / n$ polymorph at elevated temperature.[14, 19] 
However, structural instability caused by Jahn-Teller distortion and amorphization during subsequent electrochemical cycling resulted in capacity fading. $[6,30,37,40]$ The work by Islam et al. $[41,42]$ showed that $P m n 2_{1}$ (low temperature polymorph) has simplest $\mathrm{Li}^{+}$-ion migration pathway and lower energy barrier due to high symmetry of Li sites in the unit cells. This is in contrast to $P 2_{1} / n$ (high temperature polymorph) which has two symmetrically distinct Li sites in the unit cells, whose formation energies are considerably different leading to a complex migration pathway for $\mathrm{Li}^{+}$-ions. Hence, it is expected that these two polymorphs would show varying electrochemical properties.

The main focus of this study is to isolate the polymorphs of $\mathrm{Li}_{2} \mathrm{MnSiO}_{4}$ by controlling only the calcination temperature and to investigate their lithium storage performance. Two polymorphs namely, $P m n 2_{1}$ and $P 2_{1} / n$ were isolated by exercising judicial control on the calcination temperature. Among these two polymorphs, the electrochemical performance of $P m n 2_{1}$ was found to be better than $P 2_{1} / n$. Further, we could extract/insert more than one mole of lithium successfully in low temperature polymorph $\left(P m n 2_{1}\right) . P m n 2_{1}$ exhibits high storage capacity of $262 \mathrm{mAh} \mathrm{g}^{-1}$ at $0.1 \mathrm{C}$ and rate performance up to $5 \mathrm{C}$; in contrast $P 2_{1} / n$ delivers only a discharge capacity of $164 \mathrm{mAh} \mathrm{g}^{-1}$ at $0.1 \mathrm{C}$ at room temperature. Besides the role of polymorphism, it is also found that the structural stability upon cycling is critical in achieving high storage performance of silicate based cathodes presented in this study.

\section{Experimental}

\subsection{Synthesis of $\mathrm{Li}_{2} \mathrm{MnSiO}_{4} / \mathrm{C}$ polymorphs}

Carbon coated $\mathrm{Li}_{2} \mathrm{MnSiO}_{4}\left(\mathrm{Li}_{2} \mathrm{MnSiO}_{4} / \mathrm{C}\right)$ polymorphs were synthesized by two-step synthesis approach followed by high energy ball mill. All the precursors were mixed in stoichiometric ratio. Firstly, citric acid $\left(\mathrm{C}_{6} \mathrm{H}_{8} \mathrm{O}_{7}\right.$, Alfa Aesar) were dissolved in a flask with a mixture of absolute ethanol and millQ/DI water in the volume ratio of 1:2. Then manganese 
(II) acetate tetrahydrate $\left(\mathrm{Mn}\left(\mathrm{CH}_{3} \mathrm{CO}_{2}\right)_{2} 4 \mathrm{H}_{2} \mathrm{O}\right.$, Sigma Aldrich) and tetraethyl orthosilicate $\left(\mathrm{SiC}_{8} \mathrm{H}_{20} \mathrm{O}_{4}\right.$, TCI-EP-Japan) were added and the mixer was stirred for $24 \mathrm{~h}$. The sample was evaporated completely using Heidolph Hei-VAP rotary evaporator and the final precipitate was calcined at $700{ }^{\circ} \mathrm{C}$ for $8 \mathrm{~h}$ under $\mathrm{Ar}$ atmosphere. The calcined product was mixed with lithium hydroxide monohydrate $\left(\mathrm{Li}(\mathrm{OH}) \cdot \mathrm{H}_{2} \mathrm{O}\right.$, Sigma Aldrich) using high energy ball mill at $500 \mathrm{rpm}$ for $60 \mathrm{~min}$. The final product was calcined at different temperatures, between 450 ${ }^{\circ} \mathrm{C}$ and $1000{ }^{\circ} \mathrm{C}$ for $8 \mathrm{~h}$ in an $\mathrm{Ar}-\mathrm{H}_{2}$ (95:5) atmosphere to isolate the polymorphs. Two polymorphs $P m n 2_{1}$ (low temperature: $450{ }^{\circ} \mathrm{C}-800{ }^{\circ} \mathrm{C}$ ) and $P 2_{1} / n$ (high temperature: $850{ }^{\circ} \mathrm{C}$ $-1000{ }^{\circ} \mathrm{C}$ ) were isolated by controlling the calcination temperature. For further experiments, two samples which were calcined at $750{ }^{\circ} \mathrm{C}$ and $1000{ }^{\circ} \mathrm{C}$ for $8 \mathrm{~h}$ in an $\mathrm{Ar}_{2} \mathrm{H}_{2}$ (95:5) atmosphere were taken. Further, the low temperature $P m n 2_{1}$ polymorph was prepared without carbon coating (control sample) by two-step synthesis method to appraise the effect of conductive surface. Before making the slurry for the battery electrodes, the active material and acetylene black were mixed using FRITSCH premium line at $500 \mathrm{rpm}$ for $2 \mathrm{~h}[43,44]$ and then the samples were subjected to re-heating at $750{ }^{\circ} \mathrm{C}$ or $1000{ }^{\circ} \mathrm{C}$ for $8 \mathrm{~h}$ in an $\mathrm{Ar}-\mathrm{H}_{2}$ $(95: 5)$ atmosphere to retain the polymorphs.

\subsection{Material characterization}

X-ray diffraction (XRD) patterns for various samples were recorded in a Shimadzu 6000 diffractometer instrument using $\mathrm{Cu} \mathrm{K} \alpha$ radiation. FESEM and elemental mapping studies were performed using a JEOL JSM-6701F operated at $5 \mathrm{kV}$ with $10 \mathrm{~mA}$ and $15 \mathrm{kV}$ with current $2.56 \mathrm{nA}$ respectively. TEM studies were carried out using JEOL JEM - 2010. Prior to the experiments, the sample was dispersed in ethanol by sonication; a drop was loaded on Cu-grid and dried. Sorption isotherms were recorded using Nova 2200e surface 
area and pore analyzer (Quantachrome, USA). Prior to the experiment, the samples were degassed at $120{ }^{\circ} \mathrm{C}$ for overnight. The in-situ carbon was determined by ICP analysis.

\subsection{Electrochemical characterization}

$\mathrm{Li}_{2} \mathrm{MnSiO}_{4} / \mathrm{C}$ electrodes were made with the active material, carbon and binder (Kynar 2801) in the weight ratio of 65:25:10 (25\% conductive carbon includes in-situ carbon from carbonizing agent and ex-situ carbon additive). N-methylpyrrolidone (NMP) solvent was used to adjust the viscosity. The viscous slurry was coated on thin aluminium foil using doctor blade equipment. Then, the NMP was evaporated by drying the electrodes at $110{ }^{\circ} \mathrm{C}$ overnight under vacuum oven. The electrodes were then pressed using a twin roller (Hohsen Corporation). The pressed electrodes were then cut into circular discs of $16 \mathrm{~mm}$ diameter and dried at $110{ }^{\circ} \mathrm{C}$ overnight in an antechamber. The active material loading is $\sim 1.5 \mathrm{mg} \mathrm{cm}^{-2}$ (total loading $=\sim 3 \mathrm{mg}$ ). Subsequently, the 2016 coin cell was fabricated using lithium as counter electrode in an inert glove box which maintains $<5$ ppm of $\mathrm{O}_{2}$ and $<1$ ppm of $\mathrm{H}_{2} \mathrm{O}$ (MBraun Germany). 1M LiPF 6 in ethylene carbonate (EC) diethyl carbonate (DEC) (1:1 volume ratio) was used as a liquid electrolyte. The glass microfiber (GF/C) filters were used as the separator. Galvanostatic cycling was done by means of Constant Current- Constant Voltage (CC-CV) mode of cycling with the voltage window of 1.5-4.6 V at room temperature using Arbin battery cycler (Model, BT2000, USA). The cells were charged under Constant Current - Constant Voltage (CC-CV) mode and then discharged under Constant Current (CC) mode. At end of each CC mode in the charging cycle, the voltage was kept constant until it reaches theoretical capacity. The storage capacity values are calculated excluding carbon amount and only based on active material. 


\section{Results and discussion}

\subsection{Structural and morphological characterization}

Figure 1 illustrates the XRD pattern of $\mathrm{Li}_{2} \mathrm{MnSiO}_{4} / \mathrm{C}$ as a function of synthesis temperature, $450{ }^{\circ} \mathrm{C}-1000{ }^{\circ} \mathrm{C}$. With increasing the temperature, a clear transition from one polymorph to another could be seen (refer Figure 1a and 1b). The samples which are calcined at low temperature $\left(450{ }^{\circ} \mathrm{C}\right.$ to $\left.800{ }^{\circ} \mathrm{C}\right)$ exhibit $P m n 2_{1}$ polymorph. However, calcination at temperatures above $850{ }^{\circ} \mathrm{C}$ resulted in the evolution of intensive new peaks at around $22^{\circ}$ (shown in red arrow), a signature of high temperature $P 2_{1} / n$ polymorph.[13] All peaks in the sample calcined at $1000{ }^{\circ} \mathrm{C}$ correspond to high temperature $P 2_{1} / n$ polymorph. For clarity, XRD patterns of samples calcined at $750{ }^{\circ} \mathrm{C}$ and $1000{ }^{\circ} \mathrm{C}$ are shown in Figure 2. Analysis of Rietveld refinement suggests the formation of low and high temperature polymorphs of $\mathrm{Li}_{2} \mathrm{MnSiO}_{4}$ (Figure S1) and the corresponding cell parameters are listed in Table 1.[10, 13, 31, 32, 35] The in-situ carbon content on the low and high temperature polymorphs deduced from CHNX analysis were 6.5 and $4.4 \mathrm{wt} \%$ respectively. Accordingly, the ex-situ carbon additive is added to maintain total carbon content in the samples at $\sim 25$ wt\% and this was confirmed by CHNX analysis.

FESEM images of low and high temperature polymorphs are shown in Figure S2. The samples have similar morphology and are made of agglomerated particles with primary grain size in the range $40-60 \mathrm{~nm}$. Elemental mapping images (Figure S3) show uniform distribution of carbon, silicon, manganese and oxygen within the active material. The BET surface area of carbon coated $P m n 2_{1}$ and $P 2_{1} / n$ samples was estimated from $\mathrm{N}_{2}$ sorption isotherms (Figure S4). Nitrogen adsorption and desorption isotherms of these samples exhibit clear hysteresis loop of Type IV.[45]' [46, 47] The BET surface areas of these samples are 
found to be 22.06 and $20.88 \mathrm{~m}^{2} \mathrm{~g}^{-1}$ with a pore size of 3.76 and $3.80 \mathrm{~nm}$ respectively (inset of Figure S4). The pore volumes of these samples are 0.056 and $0.052 \mathrm{cc} \mathrm{g}^{-1}$ respectively.

Figure 3 shows the SAED and HRTEM images of $P m n 2_{1}$ and $P 2_{1} / n$ samples. The SAED patterns of these two samples calcined at 750 and $1000{ }^{\circ} \mathrm{C}$ confirm the formation of low and high temperature polymorphs respectively, a trend consistent with XRD patterns (Figure 2). Besides, HRTEM images also show the observed lattice fringes with $d$-spacing of $3.91 \AA$ and $2.53 \AA$ corresponding to (101) and (022) plane of $P m n 2_{1}$ and $P 2_{1} / n$ polymorphs of $\mathrm{Li}_{2} \mathrm{MnSiO}_{4}$ respectively (Figure 3b and 3d). In addition, HRTEM images also confirm presence of uniform carbon coating $(\sim 5 \mathrm{~nm})$ around the active materials.

\subsection{Lithium storage performance}

Figure 4a-4b demonstrates the lithium storage performance of low and high temperature polymorphs of $\mathrm{Li}_{2} \mathrm{MnSiO}_{4} / \mathrm{C}$ with a $\mathrm{CC}-\mathrm{CV}$ mode of cycling at room temperature. We observe a wide sloppy plateau from 4 to $4.5 \mathrm{~V}$ in the first charge cycle for both the low and high temperature polymorphs, consistent with the previous reports. $[14,15$, $18,37]$ The low temperature polymorph $\left(P m n 2_{1}\right)$ exhibits a discharge capacity of $262 \mathrm{mAh} \mathrm{\textrm {g } ^ { - }}$ ${ }^{1}$ with an average potential of $\sim 3.0 \mathrm{~V}$ at $0.1 \mathrm{C}$ corresponding to $\sim 1.6$ moles of $\mathrm{Li}^{+}$ions extraction/insertion from/into the structure respectively. On the other hand, high temperature polymorph $\left(P 2_{1} / n\right)$, delivers first discharge capacity of $72 \mathrm{mAh} \mathrm{g}^{-1}$. In the second charge cycle, this high temperature polymorph $\left(P 2_{1} / n\right)$ delivers a capacity of $250 \mathrm{mAh} \mathrm{g}^{-1}$ at $0.1 \mathrm{C}$. However, in the subsequent discharge, only one mole of lithium is inserted into its structure resulting in low capacity of $164 \mathrm{mAh}^{-1}$ at $0.1 \mathrm{C}$. In the subsequent cycles, there is a continuous capacity fade observed in $P 2_{1} / n$ sample thus losing $\mathrm{Li}^{+}$-ions during extraction and insertion processes. Further, the capacity retention of $P 2_{1} / n$ sample was only $61 \%$ of its 
second cycle discharge capacity after 10 cycles compared to $P m n 2_{1}$ sample which retains 94\% of its initial capacity (Figure $\mathbf{4 a - 4 b ) .}$

Dominko et al. $[11,40]$ demonstrated that the extraction of more one mole $\mathrm{Li}^{+}$ion from the $P m n 2_{1}$ polymorph leads to amorphization resulting in low storage performance and continuous capacity fading. Here, we show that the amorphization could be suppressed to a greater extent by providing an in-situ carbon coating around manganese silicate. Figure 4c4d demonstrates the ex-situ XRD patterns of carbon coated low and high temperature polymorphs after cycling. All the major peaks are seen corresponding to $P m n 2_{1}$ polymorph suggesting that the carbon coated $P m n 2_{1}$ retains the structure even after 30 cycles in contrast to some of the previous reports.[18, 37, 48] In the case of $P 2_{1} / \mathrm{n}$ polymorph, all the major peaks can be seen after the first charge cycle. However, the intensity of the peaks is decreased after 30 cycles, suggesting substantial changes in the crystal structure. During initial delithiation in $P 2_{1} / \mathrm{n}, \mathrm{Mn}^{2+}$ is oxidized to $\mathrm{Mn}^{3+}$ (Jahn-Teller distortion ion) for extraction of less than 1 mole of lithium and then partial reduction from $\mathrm{Mn}^{3+}$ to $\mathrm{Mn}^{2+}$ during discharge cycle as inferred from the first cycle curve (Figure $\mathbf{4 b}$ ). During second charge cycle, $\mathrm{Mn}^{2+}$ is oxidized to $\mathrm{Mn}^{3+}$ and $\mathrm{Mn}^{4+}$ for extraction of less than 2 mole of lithium. However, one mole of lithium only is inserted into the $P 2_{1} / \mathrm{n}$ crystal structure upon second charge cycle, resulting in reduction of $\mathrm{Mn}^{4+}$ to a mixture of $\mathrm{Mn}^{3+}$ and $\mathrm{Mn}^{2+}$. Thus this can increase the effect of Jahn-Teller distortion and it destroys the crystal structure, leading to amorphization, resulting in poor electrochemical performance (Figure 4b-4d).[15, 18, 37] Interestingly, $P m n 2_{1}$ exhibits reversible extraction/insertion of $\sim 1.6$ moles of $\mathrm{Li}^{+}$ions from/into the crystal structure, corresponding to facile reversible transition of $\mathrm{Mn}^{2+} / \mathrm{Mn}^{3+} / \mathrm{Mn}^{4+}$ redox reactions (Figure 4a). This reversible transition of redox couples in $P m n 2_{1}$ polymorph could be correlated to the structural stability and suppressed Jahn-Teller distortion during oxidation 
and reduction reactions (Figure 4c).[49] Thus we believe that Jahn-Teller distortion associated with the $\mathrm{Mn}^{3+}$ ions is relatively higher in $P 2_{1} /$ n compared to $P m n 2_{1}$ polymorph in this study. Further studies are needed in this direction to understand the effect of Jahn-Teller distortion in low and high temperature polymorphs.

Besides, $P m n 2_{1}$ polymorph is prepared without in-situ carbon coating (control sample). Ex-situ XRD patterns are recorded on un-coated $P m n 2_{1}$ polymorph electrode at first charge cycle $(4.6 \mathrm{~V})$ and after 10 cycles (Figure 4e). The intensity of all major peaks corresponds to $P m n 2_{1}$ polymorph decreased (amorphous) after first charge up to $4.6 \mathrm{~V}$ and 10 cycles (Figure 4e). It is also worth noting that the un-coated low temperature Pmn2 polymorph delivered discharge capacity of $148 \mathrm{mAh} \mathrm{g}^{-1}$ and retained only $49 \%$ capacity after $10^{\text {th }}$ cycles (Figure $4 \mathbf{f}$ ) while the carbon coated samples retained 94\% capacity (Figure $\mathbf{4 b}$ ). Hence, we believe that the presence of uniform carbon coating around the manganese silicate acts as a buffer layer to accommodate the strain that has been created during the electrochemical intercalation and de-intercalation in $P m n 2_{1}$. It is thus evident that the structural stability is important to achieve good lithium storage performance.

To understand further the differences in the rate performance of low and high temperature phase, we refer to the theoretical work on lithium migration pathway in $\mathrm{Li}_{2} \mathrm{MnSiO}_{4}$ polymorphs by Islam et al.[41, 42] The low temperature phase $P m n 2_{1}$ has the highest symmetry and provides simplest $\mathrm{Li}^{+}$ion migration pathway owing to $\mathrm{Li}^{+}$-ion sites in the unit cell which are symmetrically equivalent and it has similar jump distance for each direction ( $\mathrm{a}$ and $\mathrm{c})$. In sharp contrast, the high temperature phase $\left(\mathrm{P} 2{ }_{1} / \mathrm{n}\right)$ has two symmetrically distinct $\mathrm{Li}^{+}$ion sites and the formation energy of these two different sites is considerably different leading to a complex migration pathway with jump distances between $2.7 \AA$ and $3.5 \AA$.[41, 42] The activation energy for $P m n 2_{1}$ is uniform in both $a$ and $c$ 
directions approximately $1 \mathrm{eV}$. The activation energies for $P 2_{1} / n$ are not uniform, varying 0.3-1.4 eV/0.6-0.9 eV depending on the lithium hopping migration directions.[42] Hence, this complex migration pathway and activation energy of $P 2_{1} / n$ ultimately raises the energy barrier for the alkali ion migration resulting in a poor rate performance.[41, 42] Therefore, the orthorhombic phase with highest symmetry facilitates easy access to $\mathrm{Li}^{+}$-ions from the bulk of the electrode delivering enhanced rate performance in contrast to the high temperature monoclinic phase.

The voltage profiles and polarization of orthorhombic phase $\left(P m n 2_{1}\right)$ are much better than the monoclinic phase $\left(P 2_{1} / n\right)$ as shown in Figure $4 \mathbf{a}-4 \mathbf{b}$. Figure $4 \mathbf{a}$ represents the galvanostatic profile of $P m n 2_{1}$ at the second cycle. The average potentials of lithium extraction and insertion are $\sim 3.97 \mathrm{~V}$ and $\sim 3.0 \mathrm{~V}$ respectively with a voltage polarization of $0.97 \mathrm{~V}$. Single sloppy profiles are observed for the charge or discharge cycle of $P m n 2_{1}$ owing to similar activation energy in the both the hopping directions.[41, 42] On the other hand, we observe two distinct sloppy profiles for the $2^{\text {nd }}$ charge or discharge cycle for $P 2_{1} / n$ phase owing to the variation in the activation energy and hopping distance for different hopping directions.[41, 42] The corresponding average potentials of lithium extraction and insertion are $\sim 4.12,3.85 \mathrm{~V}$ and $\sim 3.16,1.8 \mathrm{~V}$ respectively resulting in voltage polarization of 1.26 and $1.43 \mathrm{~V}$ at these two plateaus. It must be mentioned here that we do not observe distinct voltage plateaus in subsequent cycles and further investigation is needed in this direction.

The rate performance of low and high temperature polymorphs is shown in the Figure 4c. The cells are cycled from $0.1 \mathrm{C}$ to $5 \mathrm{C}$ rate. After testing at $5 \mathrm{C}$, all the cells were again tested at $0.1 \mathrm{C}$. The low temperature polymorph retains $80 \%$ of its initial capacity at $0.1 \mathrm{C}$ while high temperature polymorph retains only $67 \%$ of its initial capacity. A summary of lithium storage performance of both polymorphs are listed in the Table S1. Notably, the 
capacity of $P m n 2_{1}$ phase is almost $1.5-2$ times higher compared to $P 2_{1} / n$ phase at all current rates (Table S1). Further the low temperature polymorph of $\mathrm{Li}_{2} \mathrm{MnSiO}_{4} / \mathrm{C}$ showed better cycling stability compared to $P 2_{1} / n$ polymorph (Figure 4 d). The cycling stability of $P m n 2_{1}$ polymorph observed here is the highest among the reports in literature.[11, 15, 19, 22, 26, $27] \cdot[14,21,40,50]$ For instance, a capacity retention of $90 \%$ is obtained for low temperature polymorph after 30 cycles at $0.1 \mathrm{C}$. In contrast, high temperature polymorph $P 2{ }_{1} / n$ shows only $40 \%$ of its second cycle discharge capacity (Figure 4d). As discussed, both the LMS materials were synthesized with similar morphology, mesoporosity and carbon amount. Hence, it is believed that the performance differences of two polymorphs are not biased by such factors. Thus it is evident that apart from structural stability of polymorphs, the type of polymorph is also important to achieve good lithium storage performance.

\section{Conclusions}

In summary, two polymorphs of $\mathrm{Li}_{2} \mathrm{MnSiO}_{4}$ are isolated by carefully controlling the calcination temperature. XRD patterns, HRTEM images and SAED patterns confirm the formation of the low temperature $P m n 2_{1}$ polymorph and high temperature $P 2_{1} / n$ polymorph. The electrochemical performance of $P m n 2_{1}$ polymorph was much better than $P 2_{1} / n$ polymorph. We could extract and insert more than one mole of lithium successfully from orthorhombic polymorph $\left(P m n 2_{1}\right)$. Pmn2 $2_{1}$ exhibits high lithium storage performance of 262 $\mathrm{mAh} \mathrm{g}^{-1}$ at $0.1 \mathrm{C}$ and impressive rate performance up to $5 \mathrm{C}$ at room temperature; in contrast to $P 2_{1} / n$ which delivers only $164 \mathrm{mAh} \mathrm{g}^{-1}$ at $0.1 \mathrm{C}$. Notably, the capacity of $P m n 2_{1}$ phase is almost $1.5-2$ times higher than $P 2_{1} / n$ phase at all current rates. The capacity retention of $90 \%$ is obtained for orthorhombic polymorph after 30 cycles at $0.1 \mathrm{C}$. The voltage profiles and voltage polarization of orthorhombic phase are much better than the monoclinic phase. Such perceivable difference in the rate performances and voltage profiles is explained by the 
variations in the activation energy barrier and hopping distance of $\mathrm{Li}^{+}$ion in the polymorphs. Ex-situ XRD pattern of carbon coated samples revealed that the structure was stable upon first charging up to $4.6 \mathrm{~V}$ and after 30 electrochemical cycles while un-coated samples underwent amorphization. Thus, carbon coated samples of $P m n 2_{1}$ retained $94 \%$ capacity after 10 cycles while uncoated samples retained only $40 \%$ at $0.1 \mathrm{C}$ rate. Besides the role of polymorphism, it is found that the structural stability during cycling is also critical in achieving high storage performance. This suggest that the storage performance of $\mathrm{Li}_{2} \mathrm{MnSiO}_{4}$ can be enhanced by a combination of two effects namely (i) isolating low temperature polymorph and (ii) providing in-situ carbon coating.

\section{Acknowledgements}

Authors wish to thank DARPA (USA) and NUS (MoE Tier -1) for funding this project (R265-000-452-597 and R-265-000-387-112). V.R. also thanks M. Kuezma and S. Devaraj for fruitful discussions. We also thank T. Gustafsson at Uppsala University for useful comments. 


\section{References}

[1] M. Armand, J.M. Tarascon, Nature, 451 (2008) 652-657.

[2] B. Kang, G. Ceder, Nature, 458 (2009) 190-193.

[3] J. Hassoun, S. Panero, P. Reale, B. Scrosati, Advanced Materials, 21 (2009) 4807-4810.

[4] O.K. Park, Y. Cho, S. Lee, H.-C. Yoo, H.-K. Song, J. Cho, Energy \& Environmental Science, 4 (2011) 1621-1633.

[5] P.G. Bruce, B. Scrosati, J.-M. Tarascon, Angewandte Chemie International Edition, 47 (2008) 2930-2946.

[6] M.S. Islam, R. Dominko, C. Masquelier, C. Sirisopanaporn, A.R. Armstrong, P.G. Bruce, Journal of Materials Chemistry, 21 (2011) 9811-9818.

[7] Z. Gong, Y. Yang, Energy \& Environmental Science, 4 (2011) 3223-3242.

[8] M. Armand, C. Michot, N. Ravet, M. Simoneau, P. Hovington, European patent, 826 (EP 1134 2001) A1.

[9] A. Nytén, A. Abouimrane, M. Armand, T. Gustafsson, J.O. Thomas, Electrochemistry Communications, 7 (2005) 156-160.

[10] R. Dominko, M. Bele, M. Gaberšček, A. Meden, M. Remškar, J. Jamnik, Electrochemistry Communications, 8 (2006) 217-222.

[11] R. Dominko, D.E. Conte, D. Hanzel, M. Gaberscek, J. Jamnik, Journal of Power Sources, 178 (2008) 842-847.

[12] C. Sirisopanaporn, A. Boulineau, D. Hanzel, R. Dominko, B. Budic, A.R. Armstrong, P.G. Bruce, C. Masquelier, Inorganic Chemistry, 49 (2010) 7446-7451.

[13] C. Sirisopanaporn, R. Dominko, C. Masquelier, A.R. Armstrong, G. Mali, P.G. Bruce, Journal of Materials Chemistry, 21 (2011) 17823-17831.

[14] M. Kuezma, S. Devaraj, P. Balaya, Journal of Materials Chemistry, 22 (2012) 21279-21284.

[15] S. Devaraj, M. Kuezma, C.T. Ng, P. Balaya, Electrochimica Acta, 102 (2013) 290-298. 
[16] D. Ensling, M. Stjerndahl, A. Nyten, T. Gustafsson, J.O. Thomas, Journal of Materials Chemistry, 19 (2009) 82-88.

[17] G. Zhong, Y. Li, P. Yan, Z. Liu, M. Xie, H. Lin, The Journal of Physical Chemistry C, 114 (2010) 3693-3700.

[18] R. Dominko, Journal of Power Sources, 184 (2008) 462-468.

[19] D. Rangappa, K.D. Murukanahally, T. Tomai, A. Unemoto, I. Honma, Nano Letters, 12 (2012) $1146-1151$.

[20] J. Moskon, R. Dominko, R. Cerc-Korosec, M. Gaberscek, J. Jamnik, Journal of Power Sources, 174 (2007) 683-688.

[21] V. Aravindan, K. Karthikeyan, K.S. Kang, W.S. Yoon, W.S. Kim, Y.S. Lee, Journal of Materials Chemistry, 21 (2011) 2470-2475.

[22] S. Liu, J. Xu, D. Li, Y. Hu, X. Liu, K. Xie, Journal of Power Sources, 232 (2013) 258-263.

[23] V. Aravindan, S. Ravi, W.S. Kim, S.Y. Lee, Y.S. Lee, Journal of Colloid and Interface Science, 355 (2011) 472-477.

[24] D.M. Kempaiah, D. Rangappa, I. Honma, Chemical Communications, 48 (2012) 2698-2700.

[25] V. Aravindan, K. Karthikeyan, S. Ravi, S. Amaresh, W.S. Kim, Y.S. Lee, Journal of Materials Chemistry, 20 (2010) 7340-7343.

[26] X.-F. Yang, J.-H. Yang, K. Zaghib, M.L. Trudeau, J.Y. Ying, Nano Energy, 12 (2015) 305-313.

[27] S. Aono, T. Tsurudo, K. Urita, I. Moriguchi, Chemical Communications, 49 (2013) 2939-2941.

[28] M.E. Arroyo-de Dompablo, M. Armand, J.M. Tarascon, U. Amador, Electrochemistry Communications, 8 (2006) 1292-1298.

[29] C. Lyness, B. Delobel, A.R. Armstrong, P.G. Bruce, Chemical Communications, (2007) 4890-4892.

[30] R. Chen, R. Heinzmann, S. Mangold, V.S.K. Chakravadhanula, H. Hahn, S. Indris, The Journal of Physical Chemistry C, 117 (2013) 884-893.

[31] G. Mali, A. Meden, R. Dominko, Chemical Communications, 46 (2010) 3306-3308. 
[32] M.E. Arroyo-deDompablo, R. Dominko, J.M. Gallardo-Amores, L. Dupont, G. Mali, H. Ehrenberg, J. Jamnik, E. Morán, Chemistry of Materials, 20 (2008) 5574-5584.

[33] D. Santamaría-Pérez, U. Amador, J. Tortajada, R. Dominko, M.E. Arroyo- de Dompablo, Inorganic Chemistry, 51 (2012) 5779-5786.

[34] R.J. Gummow, N. Sharma, V.K. Peterson, Y. He, Journal of Solid State Chemistry, 188 (2012) 32-

37.

[35] V.V. Politaev, A.A. Petrenko, V.B. Nalbandyan, B.S. Medvedev, E.S. Shvetsova, Journal of Solid State Chemistry, 180 (2007) 1045-1050.

[36] H. Duncan, A. Kondamreddy, P.H.J. Mercier, Y. Le Page, Y. Abu-Lebdeh, M. Couillard, P.S.

Whitfield, I.J. Davidson, Chemistry of Materials, (2011).

[37] Y.-X. Li, Z.-L. Gong, Y. Yang, Journal of Power Sources, 174 (2007) 528-532.

[38] I. Belharouak, A. Abouimrane, K. Amine, The Journal of Physical Chemistry C, 113 (2009) 2073320737.

[39] Z.L. Gong, Y.X. Li, Y. Yang, Electrochemical and Solid-State Letters, 9 (2006) A542-A544.

[40] R. Dominko, Journal of Power Sources, 184 (2008) 462-468.

[41] N. Kuganathan, M.S. Islam, Chemistry of Materials, 21 (2009) 5196-5202.

[42] C.A.J. Fisher, N. Kuganathan, M.S. Islam, Journal of Materials Chemistry A, 1 (2013) 4207-4214.

[43] V. Ramar, K. Saravanan, S.R. Gajjela, S. Hariharan, P. Balaya, Electrochimica Acta, 105 (2013) 496-505.

[44] V. Ramar, P. Balaya, Phys. Chem. Chem. Phys., 15 (2013) 17240-17249.

[45] C.K. Lee, A.S.T. Chiang, C.S. Tsay, in, Trans Tech Publications, 1995, pp. 21-44.

[46] J.H. de Boer, B.G. Linsen, T. van der Plas, G.J. Zondervan, Journal of Catalysis, 4 (1965) 649-653.

[47] B.C. Lippens, J.H. de Boer, Journal of Catalysis, 4 (1965) 319-323.

[48] M. Moriya, M. Miyahara, M. Hokazono, H. Sasaki, A. Nemoto, S. Katayama, Y. Akimoto, S.-i. Hirano, Journal of The Electrochemical Society, 161 (2014) A97-A101. 
[49] A. Bhaskar, M. Deepa, T.N. Rao, U.V. Varadaraju, Journal of The Electrochemical Society, 159 (2012) A1954-A1960.

[50] T. Muraliganth, K.R. Stroukoff, A. Manthiram, Chemistry of Materials, 22 (2010) 5754-5761. 


\section{Figure Captions:}

Figure 1. (a) XRD patterns of $\mathrm{Li}_{2} \mathrm{MnSiO}_{4} / \mathrm{C}$ polymorphs $\left(P m n 2_{1}\right.$ and $\left.P 2_{1} / n\right)$ as a function synthesis temperature $\left(450-1000{ }^{\circ} \mathrm{C}\right)$ (arrow in black colour shows increase in temperature) and (b) polymorph trends of $\mathrm{Li}_{2} \mathrm{MnSiO}_{4} / \mathrm{C}$ over synthesis temperature.

Figure 2. XRD patterns of high and low temperature polymorphs of $\mathrm{Li}_{2} \mathrm{MnSiO}_{4} / \mathrm{C}$, (a) $P 2_{1} / n$ polymorph synthesized at $1000{ }^{\circ} \mathrm{C}$ and (b) $P m n 2_{1}$ polymorph synthesized at $750{ }^{\circ} \mathrm{C}$.

Figure 3. SAED patterns and HRTEM images of low and high temperature polymorphs of $\mathrm{Li}_{2} \mathrm{MnSiO}_{4} / \mathrm{C}$, (a-b) $P m n 2_{1}$ and (c-d) $P 2_{1} / n$.

Figure 4. (a) Charge and discharge profiles of $P m n 2_{1}$ polymorph up to 10 cycles at $0.1 \mathrm{C}$, (b) Charge and discharge profiles of $P 2_{1} / n$ polymorph up to 10 cycles at $0.1 \mathrm{C}$; Ex-situ XRD of $\mathrm{Li}_{2} \mathrm{MnSiO}_{4} / \mathrm{C}$ polymorphs after the first charge at $4.6 \mathrm{~V}$ (red) and after 30 cycles (black), (c) $P m n 2_{1}$ polymorph and (d) $P 2_{1} / \mathrm{n}$ polymorph, (e) Ex-situ XRD of Pmn2 $2_{1}$ polymorph of $\mathrm{Li}_{2} \mathrm{MnSiO}_{4}$ sample without in-situ carbon coating after the first charge up to $4.6 \mathrm{~V}$ (red) and after 10 cycles (black), (substrate peak is marked with symbols, \#) and (f) Cyclic behaviour of un-coated $P m n 2_{1}$ polymorph sample at $0.1 \mathrm{C}$.

Figure 5. Lithium storage performance of $\mathrm{Li}_{2} \mathrm{MnSiO}_{4} / \mathrm{C}$ polymorphs at room temperature, (a) Voltage polarization of $P m n 2_{1}$ in the $2^{\text {nd }}$ cycle, (b) Voltage polarization of $P 2_{1} / n$ in the $2^{\text {nd }}$ cycle, (c) Rate performance of $P m n 2_{1}$ and $P 2_{1} / n$ polymorphs and (d) Cycling stability of $P m n 2_{1}$ and $P 2_{1} / n$ polymorphs up to 30 cycles (capacity values are calculated based on the active material weight). 


\section{Table}

Table 1. Cell parameters for the low and high temperature polymorphs of $\mathrm{Li}_{2} \mathrm{MnSiO}_{4} / \mathrm{C}$.

\begin{tabular}{ccccc}
\hline Polymorphs & $\mathrm{a}(\AA)$ & $\mathrm{b}(\AA)$ & $\mathrm{c}(\AA)$ & $\mathrm{V}\left(\AA^{3}\right)$ \\
\hline$P m n 2_{1}$ & $6.305(4)$ & $5.381(5)$ & $5.001(5)$ & 169.68 \\
$\left(\right.$ at $\left.750^{\circ} \mathrm{C}\right)$ & & & \\
\hline$P 2{ }_{1} / n$ & $6.312(5)$ & $10.898(6)$ & $5.055(4)$ & 347.81 \\
$\left(\right.$ at $\left.1000^{\circ} \mathrm{C}\right)$ & & & & \\
& & & & \\
\hline
\end{tabular}




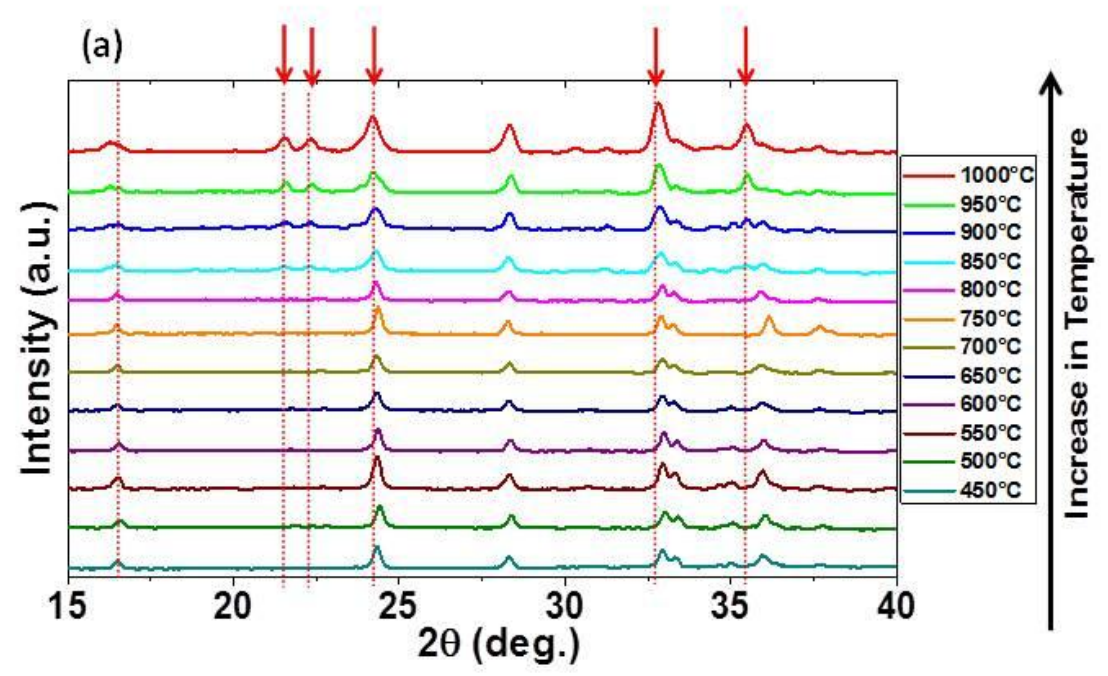

(b) Polynorph trends of $\mathrm{Li}_{2} \mathrm{MnSiO}_{4} / \mathrm{C}$ over synthesis temperature

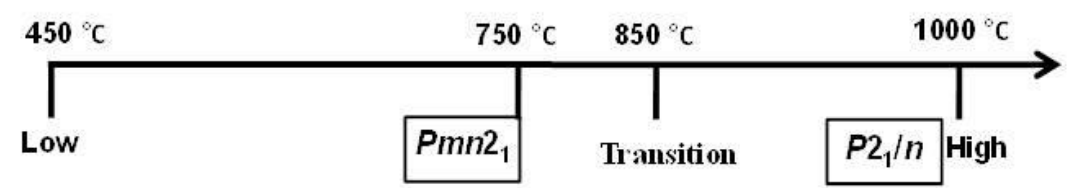

Figure 1

V. Ramar and P. Balaya 


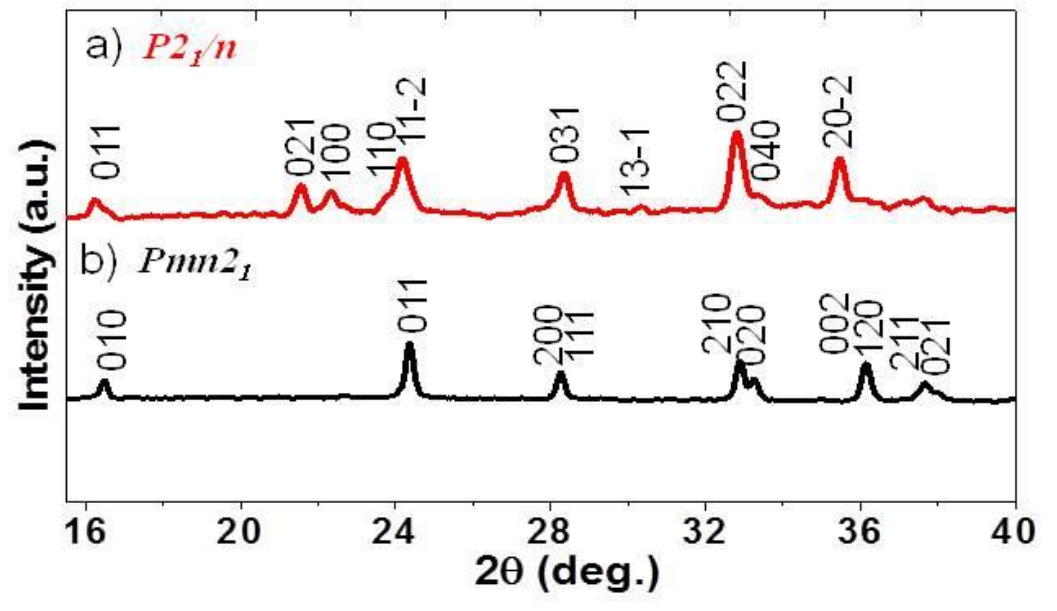

Figure 2

V. Ramar and P. Balaya 

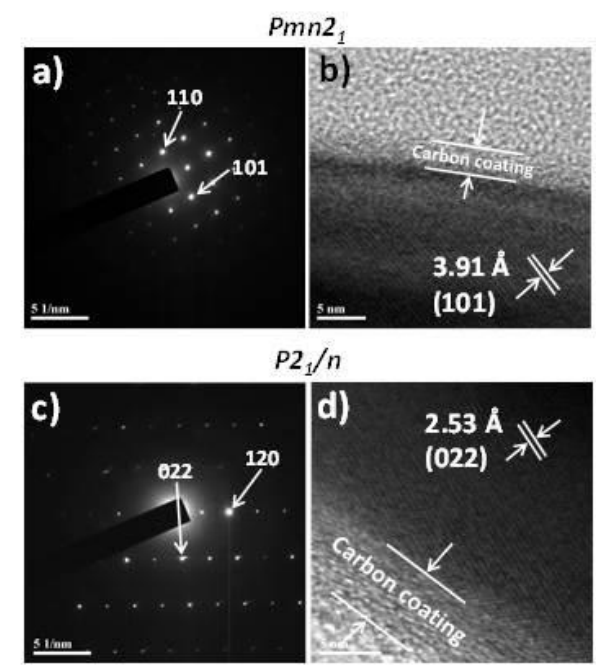

Figure 3

V. Ramar and P. Balaya 

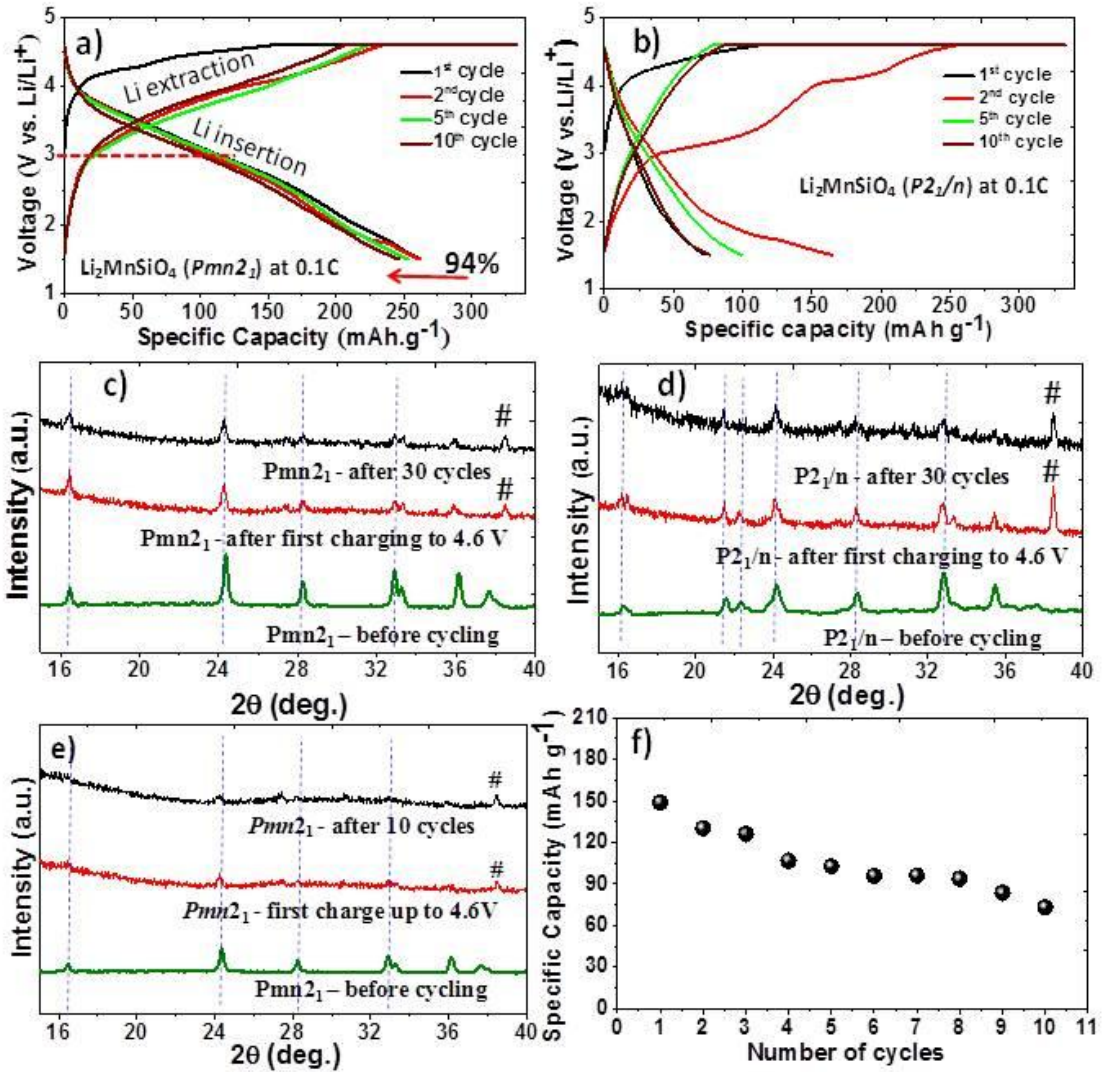

Figure 4

V. Ramar and P. Balaya 

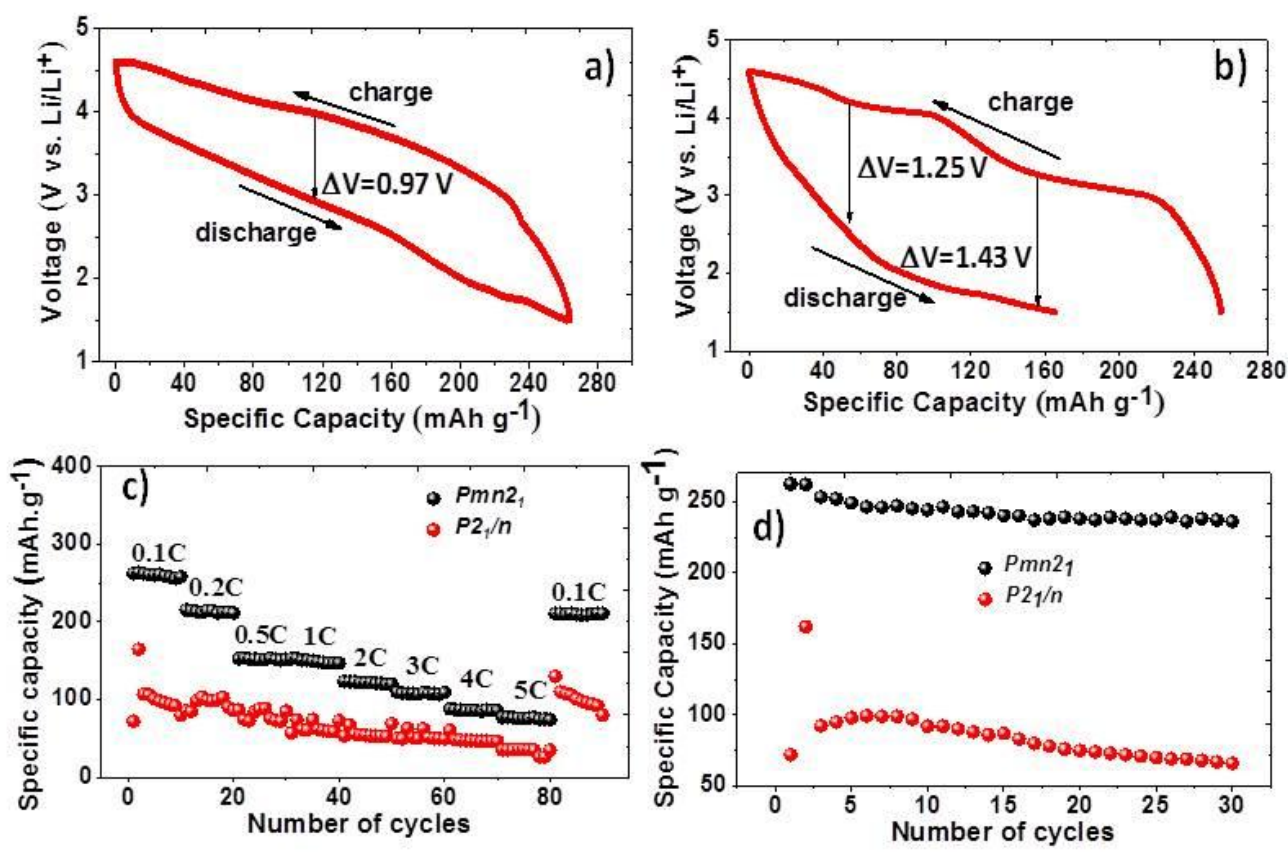

Figure 5

V. Ramar and P. Balaya 


\section{Graphical Abstract}

Electrochemical performance of $\mathrm{Li}_{2} \mathrm{MnSiO}_{4}$ depends on polymorphs investigated; low temperature orthorhombic $\left(P m n 2_{1}\right)$ phase has almost twice the capacity compared to high temperature monoclinic $\left(P 2_{1} / n\right)$ phase.

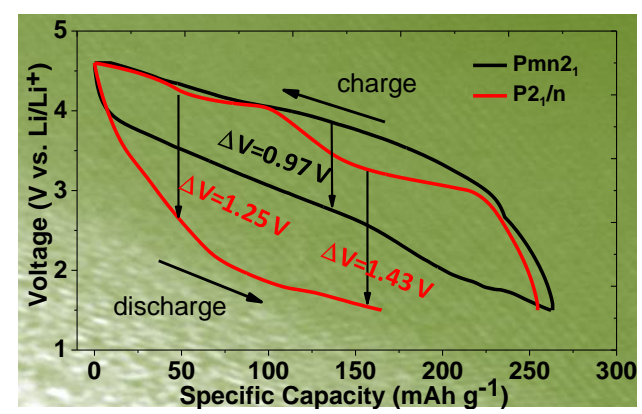

